\title{
LA RECREACIÓN POÉTICA DEL TIEMPO EN LA NARRATIVA DE CARMEN MARTÍN GAITE
}

\author{
María Jesús Orozco Vera
}

\begin{abstract}
“...El tiempo es especialmente significativo para el hombre, porque es imposible separarlo del concepto del ser (...) Lo que llamamos el yo, la persona o el individuo, se experimenta y se conoce sólamente contra el fondo de una situación de momentos temporales."
\end{abstract}

(Hans Meyerhoff: Time in Literature)

Uno de los ejes vertebradores de la novela contemporánea- como ha señalado la críticalo constituye la problemática temporal. Así lo ha manifestado, por ejemplo, Mariano Baquero Goyanes cuando afirma que "el tiempo" se define como "el único personaje de la novela moderna" (BAQUERO GOYANES, 1963). Dicho aspecto ocupa un lugar destacado en la obra de novelistas de la talla de Marcel Proust, Willian Faulkner, Virginia Woolf, Thomas Mann y James Joyce; novelistas que proyectarán su influencia en narradores españoles contemporáneos, entre los que merecen mencionarse a Gonzalo Torrente Ballester, Luis Martín Santos, Juan Marsé, Esther Tusquets, Carmen Martín Gaite, Francisco Ayala y Miguel Delibes, entre otros.

El escritor contemporáneo experimenta generalmente en sus obras una conciencia angustiosa del tiempo, dolorosa experiencia que contribuye a forjar el anhelado encuentro consigo mismo, la búsqueda de su identidad más auténtica. Dicho proceso le permite analizar las raíces de su pasado y los pilares de su presente y, al mismo tiempo, le induce a bucear en el mundo de los sueños, de la imaginación, del subconsciente. Por otra parte, hay que señalar que en su escritura se plantea también la configuración de una nueva estructura temporal que rechaza el orden cronológico lineal objetivo. Destaca, en este sentido, la recreación poética de la memoria y la configuración del tiempo subjetivo, ahistórico, basado en la experiencia, en las sensaciones y emociones vividas; desterrando por tanto relojes y calendarios.

En definitiva, en el marco de las profundas renovaciones que ha experimentado la novela contemporánea se manifiesta una nueva dimensión temporal que se sustenta en la durée señalada por Henri Bergson, una dimensión psicológica, vivencial que quedó sutilmente delimitada por Virginia Woolf en su novela Orlando cuando se refiere a la extraordinaria diferencia que caracteriza al tiempo medido por el reloj con respecto al de las vivencias:

"Una vez instalada en la mente humana, una hora puede prolongarse cincuenta o cien veces lo que una hora de reloj; y por otra parte, una hora puede estar cuidadosamente representada en el tiempo de la mente por un segundo. Esta 
extraordinaria discrepancia entre el tiempo del reloj y el tiempo de la mente es menos conocida de lo que debiera y exige una profunda investigación” (WOOLF, 1993,P.71)

La narrativa de Carmen Martín Gaite se sitúa en esta línea estética y se aventura, por tanto, hacia la búsqueda de un nuevo horizonte temporal que refleje las vivencias, las emociones, los sentimientos. Dicha circunstancia merece conectarse con su concepción del acto literario, de la creación poética. La escritora salmantina ha señalado en ocasiones la capacidad comunicativa, conversacional de la literatura, donde se implican la búsqueda de un interlocutor ideal a quien dirigir el mensaje y la inmersión en una temporalidad que se sustenta en las vivencias, en lo subjetivo, que rechaza los efectos devastadores de la cronología histórica. La creación literaria surge en ese contexto, con las características señaladas y se define como un sucedáneo de la conversación. Así lo ha manifestado Carmen Martín Gaite en una entrevista reciente:

“...si siempre pudiéramos hablar bien con toda la gente tal como queremos y tuviéramos un tiempo, un plazo narrativo, una pausa para hablar y ser escuchados y escuchar quizá no escribiríamos." (SOLER SERRANO: 1976, TVE)

Su obra constituye, por tanto, un reencuentro con el tiempo, un tiempo ahistórico, vivencial, donde es posible dialogar, conversar, donde puede conocerse a sí misma. En consecuencia, la cronología de sus novelas y relatos no implica una suma organizada de años, sino una dimensión nueva donde la evocación se superpone a los momentos presentes, donde el sueño y la ensoñación irrumpen en la realidad para crear un tiempo propio, armonioso y distendido, ajeno al ritmo vertiginoso y destructivo que sugieren los relojes y calendarios. La narrativa de Carmen Martín Gaite se inserta, por otra parte, en el proceso de renovación de la novela española contemporánea que ya se apuntaba en la denominada Generación del 50 o de Medio Siglo, generación donde la sitúa la crítica, junto a escritores como Ignacio Aldecoa, Jesús Fernández Santos, Juan García Hortelano, Juan Goytisolo, Luis Goytisolo, Alfonso Grosso, Juan Marsé, Ana Mª Matute, Rafael Sánchez Ferlosio y Esther Tusquets.

Es significativo destacar, además, que por estos años el aislamiento cultural que había caracterizado a España en la inmediata postguerra se rompió de forma paulatina. A ello contribuyó, entre otras cosas, el carácter flexible de la censura, puesto que fue posible la difusión de novelas de los grandes renovadores del género. Así, por ejemplo, se dieron a conocer las obras de Hemingway, Faulkner, Sartre y Camus. Es importante reseñar también con respecto a Carmen Martín Gaite, que, si bien algunas de sus obras- como Entre visillos(1957), manifiestan un carácter testimonial, una orientación sociológica- modalidad que asumieron preferentemente los escritores de su Generación-, gran parte de sus novelas y relatos constituyen creaciones más innovadoras y experimentales, más interiorizadas y subjetivas. En esta última vertiente merecen mencionarse sus novelas El cuarto de atrás (1978) y El balneario (1954). A ellas deben sumarse sus relatos "Lo que queda enterrado" (1958), "La oficina" (1954), "Variaciones sobre un tema" (1967), "La chica de abajo" (1953) y "Tarde de tedio" (1970).

Precisamente en este corpus se centra el análisis de la obra de la escritora salmantina que abordaré a continuación y que permitirá delimitar la problemática temporal en el marco 
de la creación poética, no sólo como tema sino también como técnica innovadora, cuyas pautas se proyectaron de forma novedosa en la narrativa de Marcel Proust, Virginia Woolf, Franz Kafka, Thomas Mann y James Joyce.

Con respecto al leit-motiv del tiempo hay que señalar su presencia notable en la narrativa de Carmen Martín Gaite, de tal forma que ha llegado a constituirse en uno de los temas centrales de su obra. Algunos críticos- como Isabel Butler y Carmen Alemany- han señalado su importancia en la configuración, no sólo de sus novelas y relatos, sino también de sus artículos y apuntes (BUTLER DE FOLEY, 1984 y ALEMANY BAY, 1990). Así aparece, por ejemplo, en novelas como Ritmo lento (1963) y El cuarto de atrás, en relatos como "Tarde de tedio" y "Lo que queda enterrado" y en artículos y apuntes como "Recetas contra la prisa", "El pulso de lo cotidiano", "La intuición del futuro" y "Habitar el tiempo".

La escritora salmantina manifiesta a través de su obra el rechazo de la dimensión temporal objetiva que caracteriza a una sociedad moderna que se rige por la prisa, por la incomunicación, por el implacable transcurso de las horas, por el vertiginoso ritmo de las estaciones y de los años. En este marco opresivo la existencia cotidiana se transforma en una muerte en vida, en una existencia rutinaria donde agoniza la propia identidad del ser. Así se caracteriza, por ejemplo, en "La oficina" la incomunicación que padecen sus personajes, sumidos en una monótona tarea y en un tiempo implacable que pondrá fin a la vida de Matías Manzano, sin que su paso por el mundo sea significativo. De manera similar, en el relato "Tarde de tedio" se manifiesta la existencia monótona y vacía de la señora Cuevas, limitada a ocuparse en tareas hogareñas, sin alteraciones, condenada a "matar el tiempo" con visitas a la modista y a la peluquería. Pero quizás esta amenaza del tiempo, esta lucha que los personajes que protagonizan la narrativa de Carmen Martín Gaite deben entablar con él se manifieste de forma más dramática en El balneario. En dicha novela breve la señorita Matilde percibe con angustia el inevitable transcurso del tiempo y la monotonía de sus días solitarios, ante los cuales sólo es posible ocupar, de forma rutinaria, las horas vacías y eternas:

"Las cinco y cuarto todavía. Bajará. !Qué va a hacer! Hasta las nueve que se cena...!Cuánta tarde queda por matar todavía! Matar la tarde. Irla matando célula por célula, minuto por minuto, y verla cómo va perdiendo sangre, sin ningún entusiasmo tampoco por la muerte, porque es como un trabajo rutinario, de oficina, el de matar la tarde. No hay riesgo, no hay opción a soluciones diferentes. Irse llenando los dedos de la sangre de la tarde, una sangre cenicienta y templada que se escurre como arena, que ni siquiera deja mancha". ${ }^{1}$

En defintiva, la narrativa de Carmen Martín Gaite refleja una dimensión temporal opresiva que se proyecta en los hombres y mujeres que protagonizan una "lucha" angustiosa e infructuosa contra el tedio y el hastío de su existencia. Así, se aventuran sin rumbo en un viaje sin retorno donde se diluye su identidad para sobrellevar el peso de los actos rutinarios e intrascendentes. Dicha actitud ha sido señalada por Isabel Butler cuando

\footnotetext{
${ }^{1}$ MARTín GAITE, C. (1994, El balneario, Cuentos completos, Madrid, p. 235). Todos los relatos analizados en este estudio, junto con la novela breve El balneario, aparecen en este volumen conjunto. Por tanto, en citas sucesivas se anotará tras el texto, entre paréntesis, sólo el número de la página o páginas correspondientes.
} 
afirma que estos personajes "tratan de defenderse del aburrimiento mediànte la ejecución de acciones irrelevantes". Sin embargo, todo ello se transforma en un círculo vicioso que no ofrece alternativas, puesto que la sensación de hastío alterna con la angustia "al sentirse los personajes irremisiblemente apremiados por el tiránico poder del tiempo que no espera." (BUTLER DE FOLEY, 1984: p. 18)

Pero, además, la opresión ejercida por el tiempo debe completarse con la función que asume el marco espacial, entorno asfixiante y opresivo que limita también la existencia de los hombres y mujeres que protagonizan la narrativa de Carmen Martín Gaite. Así, espacios cerrados como la oficina ("La oficina"), la cafetería ("Variaciones sobre un tema"), el marco hogareño ("Tarde de tedio") y El cuarto de atrás contribuyen también a forjar la imagen de una sociedad que se sumerge en la rutina, la prisa, la incomunicación y el desengaño. En dichos espacios es importante destacar el carácter recurrente de algunos objetos que simbolizan la acción destructiva del tiempo y el ritmo vertiginoso que caracteriza al mundo contemporáneo. Así por ejemplo relojes y calendarios se constituyen en símbolos que, con bastante frecuencia aparecen asociados a la esclavitud temporal que padecen los personajes. En "Variaciones sobre un tema", por jemplo, la protagonista hace referencia en ocasiones a ciertas horas que han sido significativas en el pasado. De esta forma relata su primera visita a la ciudad y el momento en que"estaban marcadas, efectivamente, las cuatro y media en un reloj que presidía el gran café bullicioso"(p.14) Respecto al calendario es significativo señalar que su presencia en el relato "La oficina" determina una costumbre, un acto rutinario que implica la inmersión en lo intrascendente, incluso la pérdida de identidad, sugerida de forma poética por el desgaste del nombre. Así, Matías Manzano, el oficinista "Se había acostumbrado a quitar las hojas del calendario, a bostezar, a ponerse la bufanda (...) Se había acostumbrado, sobre todo, a sentir que a su nombre se le iban desgastando las esquinas como a un viejo canto rodado." (p. 19)

Esta sensación de opresión, de esclavitud, de rutina que llevan implícitos estos símbolos, como expresión de una temporalidad cronológica objetiva, se configura poéticamente en El cuarto de atrás, cuando la narradora-protagonista, Carmen Martín Gaite, contrapone el espacio abierto de la ciudad a la casa de sus familiares, marco opresivo, anquilosado en rígidos moldes que aparece simbolizsado a través del sonido del reloj:

\footnotetext{
"Afuera, la ciudad bulliciosa invitaba a la aventura (...) frente a ella se me proyectaba todo el bostezo de la casa con su insoportable tictac de relojes y su relucir inerte de plata y porcelana, templo de orden, sostenido por invisibles columnas de ropa limpia, planchada y guardada dentro de cómodas, ajuar de cama y mesa, pañitos bordados, camisas almidonadas, colchas, entredoses, encajes, vainicas..." (p. 78)
}

El tiempo se define, por tanto, como una amenaza que esclaviza a la humanidad y la arrastra en su ritmo vertiginoso hacia una muerte en vida que se caracteriza por la rutina y el hastío, por la repetición de actos banales e intrascendentes. Los personajes de las novelas y relatos de Carmen Martín Gaite sienten la acción corrosiva del tiempo. Su presencia en sus vidas constituye una constante, una obsesión, un terrible peso del que intentan liberarse. Así, es significativo que prácticamente en todas sus obras los protagonistas se refieran a tardes interminables, a determinadas horas del día o de la noche, a relojes que acechan y rítmicamente rompen el silencio. Además, para evitar el hastío y la soledad ocupan casi 
exclusivamente el tiempo en un trabajo rutinario, como Matías y Mercedes en "La oficina", o se amparan en grupos humanos donde no tienen que tomar ninguna iniciativa, sólo liberarse de un tiempo que les amenaza; como sucede, por ejemplo, en El balneario y en "Tarde de tedio". Incluso asumen, en último término, evadirse de la realidad y sumirse en la atmósfera evanescente del sueño, como puede apreciarse en El balneario y "Lo que queda enterrado".

Sin embargo, frente a este acto de "matar el tiempo", de ocuparlo, de rellenarlo con tareas rutinarias, insignificantes y evasivas que mitiguen el aburrimiento, la escritora salmantina propone "habitar el tiempo". Así lo proclama, por ejemplo, en su obra ensayística El cuento de nunca acabar (1983), cuando se refiere a esta apreciación temporal donde se funden la memoria y la creación poética. Surge, de esta forma, una actitud positiva que se manifiesta en el hecho de valorarlo, de vivirlo armoniosamente:

"Los verdaderos esfuerzos de imaginación son los que tiene uno que hacer para bordar en las telas usadas y con los hilos que se tengan a mano. No en el desenfreno de salir a comprar telas nuevas, trajes nuevos, cuadernos nuevos, bolígrafos nuevos, hilos nuevos; pretextos para encubrir nuestra incapacidad de bordar o escribir en el bastidor de lo que se tiene. De nada te servirá lo nuevo tampoco si no lo haces tuyo.(...) Con el tiempo pasa igual, si te andas escapando siempre de él, es una enfermedad con recaída. Cuando espantas el tiempo no lo vives. Vivirlo es lo único que te compensa del deterioro que va dejando en ti. Y vivirlo es usarlo, bordar en él." (p. 188)

Este hecho de "habitar el tiempo" (de forma positiva) frente al acto de "matarlo" (de rechazarlo) aparece con frecuencia en las novelas y relatos de Carmen Martín Gaite, obras de creación que se constituyen, en ocasiones, en profundas reflexiones sobre el sentido de la vida y sus relaciones con la temporalidad. La contraposición entre estas dos posibles relaciones que todo ser humano puede entablar con el tiempo aparece reflejada, por ejemplo, en "La chica de abajo". En dicho relato Francisca se refiere a las horas dedicadas a tareas cotidianas (lavar, limpiar, comer, hacer recados,), un tiempo que "Ni siquiera lo sufría, porque no le parecía tiempo suyo" (p. 278) En cambio, todo era distinto, cuando acompañada de su amiga Cecilia, se recreaba en sueños y fantasías "Durante horas enteras. Durante años y siglos", en una nueva dimensión temporal donde no tenían cabida la rutina de los actos cotidianos.. (p. 277) De manera similar, en el relato "Variaciones sobre un tema", Andrea, al reflexionar sobre su vida pasada, comprende que el verdadero sentido no consiste en rememorar datos, fechas insignificantes, sino en asumir el valor de las vivencias que la marcaron, en encontrar una vía armoniosa que la condujese hacia un tiempo más auténtico:

“....al necesitar preguntarse por el sentido de semejantes vanos recuentos, a fuerza de buceos en su propio pensar, vino a comprender Andrea poco a poco que no era una cronología de su vida a lo largo del período vivido en la ciudad lo que andaba buscando. Se trataba más bien, por el contrario, de una voluntad de rechazar las cronologías aceptadas hasta entonces y rastrear una pista del tiempo menos falaz, y por este camino llegó a estar clara una cosa: la falta de sincronización entre el lenguaje del reloj o del calendario y el curso real del tiempo, que unas veces anda llevándonos en él y dejándonos habitar los paisajes a que nos asoma, y otras, las más, 
desconectado de nosotros igual que un tren vacío de cuya llegada a las estaciones llevamos, eso sí, puntual cuenta." (p. 14)

Es significativo señalar, por otra parte, que esta dimensión temporal subjetiva, creativa y armoniosa, se proyecta en un marco físico determinado; destacan así, espacios generalmente abiertos que incitan a la ensoñación y a la experimentación gozosa de momentos eternos, atemporales. En este ámbito espacial merecen considerarse los alrededores de El balneario, con su "paisaje verde y tranquilo" (p. 243), el pinar solitario donde María, protagonista de "Lo que queda enterrado", encontró una forma de "salirse del tiempo" (p. 64) y el parque bañado por las luces del ocaso, tan recurrente en "Variaciones sobre un tema", que permitió a Andrea experimentar una relación armoniosa con el tiempo. Por último, cabe apuntar también la incorporación de espacios imaginarios, maravillosos, como la isla de Bergai y Cúnigan en El cuarto de atrás.

Pero, además, junto a estos marcos naturales y libres, merecen destacarse algunos espacios cerrados que se caracterizan como lugares adecuados para entregarse al acto de habitar el tiempo. Es significativo considerar, no obstante, que dicho entorno se define por el desorden de los objetos que lo integran y el carácter de apertura que llevan implícitos la ventana y el balcón. Ambos motivos presentan un significado peculiar en las novelas y relatos de Carmen Martín Gaite, puesto que conectan el espacio cerrado con el espacio abierto y esta circunstancia implica la apertura hacia otros mundos posibles creados por la imaginación. En este sentido cabe apuntar también que el hecho de asomarse a las ventanas y balcones expresa poéticamente la búsqueda de la libertad y el anhelado encuentro del ser consigo mismo. Esta simbología se proyecta también en un ensayo de la escritora salmantina titulado precísamente Desde la ventana (1987), marco privilegiado donde se sitúa Carmen Martín Gaite para reflexionar sobre su identidad como mujer y como escritora. A propósito de esta conexión entre sus novelas y relatos y el citado ensayo, Enma Martinell ha señalado la recurrencia de la ventana y del balcón. A ellos se suma el acto de asomarse, que experimentan practicamente todos los personajes como un intento de sumirse en una temporalidad suspendida, donde sólo es posible la reflexión, la ensoñación y el logro de la propia identidad:

“...el acercamiento a la ventana, al balcón, a la terraza, responden a la voluntad de estar solo, de ser uno mismo por unos momentos que se llenarán con recuerdos, con sueños, o quizás sólo con una suspensión de todo pensamiento." (MARTINELL, 1987: p. 20)

Estos espacios- la ventana, el balcón, la terraza- se identifican con una temporalidad sin límites como corresponde a las vivencias y al hecho de experimentar momentos sublimes, atemporales, donde se manifiestan el sueño y el ensueño. Por tanto, los personajes de las novelas y relatos de Carmen Martín Gaite se sumergen en ese "tiempo sin tiempo" que implica la contemplación, la delectación morosa de un paisaje urbano o un entorno natural que se vislumbran desde un balcón, desde una ventana. En esos momentos de ensoñación se enajena, por ejemplo, Matías Manzano, protagonista de "La oficina", cuando contempla su barrio, desde el balcón de su casa, "algunas noches de Agosto" (p. 29). De manera similar María en "Lo que queda enterrado" permanecía muchas horas asomada a la ventana y en la 
quietud de esas noches de luna encontraba la paz que necesitaba su espíritu. Por último, en El balneario la señorita Matilde contempla el paisaje desde una ventana, mientras imagina un anhelado cambio en su existencia monótona y solitaria:

"La señorita Matilde se estremece en su ventana. También a este balneario pueden llegar un día unos dedos desconocidos e invisibles que lo transformen, que lo vacíen de su contenido habitual. Son como ráfagas que pasan una vez, como mensajes indescifrables, como oscuras y fugaces amenazas o promesas tal vez. Aunque se disipen igual que las nubes de tormenta, sin llegar a ser lluvia. Aunque no duren más que el tiempo de una siesta." (p. 245)

En definitiva, la ensoñación, el despliegue de la capacidad imaginativa, constituye una de las fórmulas mágicas que Carmen Martín Gaite señala para habitar el tiempo. Sin embargo, muy estrechamente unida a ella se delimita otro aspecto clave en la narrativa de la autora, la comunicación. La palabra constituye, por tanto, un medio privilegiado para experimentar de forma positiva el tiempo, pues a través de la misma- ya sea oral o escritahombres y mujeres pueden moldear su tiempo y establecer con él una relación cordial y armoniosa, que les augura la búsqueda de su propia identidad. Así, los protagonistas de las novelas y relatos de Carmen Martín Gaite despliegan morosamente hechos pasados que se funden con el presente y se sitúan en los ilimitados márgenes de la intemporalidad. En esta recreación del pasado es significativo destacar la presencia de "hilos" de "ataduras" y de verbos como "enhebrar", "tejer", que van marcando el ritmo de la memoria a través del tiempo. Así, por ejemplo, en "La oficina" aparece la expresión "reemprender el hilo" (p. 31) y en El cuarto de atrás, "enhebrar los recuerdos" (p. 128). Expresiones similares son también frecuentes en El balneario, cuando la señorita Matilde, al intentar recordar sin resultado, se siente "como una araña" que pende de un "tenue hilo" y decide, por tanto, tenderle ese "hilo" a Carlos, su marido, para que le ayude a "tejerlo" (p. 204).

Este afán de recuperar ese tiempo olvidado, de rescatar la memoria, de establecer un orden que se configure a través de las emociones, de los sentimientos, está presente como "hilo" conductor en la obra de Carmen Martín Gaite. Especialmente en aquellos momentos de soledad, donde el tiempo parece detenerse y los recuerdos afloran a la superficie reclamados por el pensamiento y por la palabra. La escritora salmantina ha expresado simbólicamente este acto de "enhebrar", de organizar los hechos pasados en su novela El cuarto de atrás, cuando asocia el desorden del espacio físico con el de la mente. Así, en ese recinto caótico permanecen agazapados los recuerdos, esperando ser rescatados, iluminados por la memoria:

“...Al comedor aquel también ellos lo llamaban "el cuarto de atrás", (...) me lo imagino (...) como un desván del cerebro, una especie de recinto secreto lleno de trastos borrosos, separado de las antesalas más limpias y ordenadas de la mente por una cortina que sólo se descorre de vez en cuando; los recuerdos que pueden darnos alguna sorpresa viven agazapados en el cuarto de atrás, siempre salen de allí, y sólo cuando quieren, no sirve hostigarlos." (p. 91)

Hay que señalar, por otra parte, que los personajes que protagonizan las novelas y relatos de Carmen Martín Gaite son seres solitarios que, en ocasiones, anhelan encontrar un interlocutor ideal con el que podrán "habitar el tiempo", evocando hechos pasados, deleitándose en la rememoración, sin sentir las presiones de los acontecimientos cotidianos, compartiendo anhelos y ensueños. Este problema de la incomunicación- que permite 
caracterizar a la sociedad española de su época- lo aborda la escritora salmantina a partir de la búsqueda de un interlocutor, un destinatario deseado que se verá reflejado en novelas como Ritmo lento (1963), Retahilas (1974) y El balneario (1954). Así, por ejemplo, en la primera novela, David se refiere a las conversaciones "siempre incompletas, pendientes de un día para otro" que mantenía con Gabriela, charlas que para él eran "importantísimas" (p. 150), aunque sospechaba que ella no las valoraba tanto. (p. 150). De la misma forma en Retahílas, Eulalia comprende, tras años de matrimonio, que en su marido nunca encontró al interlocutor con el que compartir su vida y su tiempo, pue él no sabría "habitar" ese "momento", para ella irrepetible, ni ese lugar que quedaría gravado en su memoria. (p. 137). Por último, en El balneario la señorita Matilde se sumerge en las profundidades del sueño, para encontrar un interlocutor ideal que imprima sentido a su existencia anodina y solitaria.

Este leit-motiv se repetirá incluso en su obra ensayística La búsqueda del interlocutor y otras búsquedas (1982) y aparecerá de nuevo en otra novela posterior, El cuarto de atrás (1978), novela en la que se realiza de manera armoniosa ese encuentro anhelado, protagonizado por la autora, Carmen Martín Gaite, y por Alejandro, el hombre vestido de negro que acude a visitarla con el objeto de hacerle una entrevista. Así, se configura un diálogo distendido, fluido, sin prisa, donde surgen momentos gratos de la vida de la escritora, como aquellas tardes de juegos y de divagaciones en el cuarto de atrás, sus paseos por Madrid y sus gratas experiencias literarias. A través de la palabra la escritoraprotagonista experimenta el acto de habitar el tiempo, de recrearlo, de imprimirle su propio ritmo, en función del impacto emocional que ha provocado en su vida. Por tanto, la relación con el tiempo ya no se caracteriza como dependencia, esclavitud o amenaza, sino como un encuentro placentero y armónico que se establece en otra dimensión temporal. Es decir, se trata de un tiempo subjetivo, ahistórico, forjador de momentos eternos donde el ser abraza su propia identidad, su yo más auténtico. En esta dimensión se aventuran Carmen Martín Gaite y el hombre de negro, como queda reflejado en El cuarto de atrás:

\begin{abstract}
"Ahora ya he comprendido claramente que no tiene prisa ni lleva programa ni se esfuerza por agotar temas, todo queda insinuado, esbozado, como en una danza cuyos pasos vamos ensayando juntos, a golpe de improvisación. Tenemos mucha noche por delante, un espacio abierto, plagado de posibilidades." (p. 106)
\end{abstract}

Esta recreación morosa en el tiempo, que conlleva el acto de habitarlo, permite conectar a Carmen Martín Gaite con Marcel Proust, puesto que en este acto está implícito el rechazo del orden cronológico objetivo y, como contrapartida, la inmersión en un tiempo subjetivo, psicológico, regido por el despliegue de las emociones y de los sentimientos. En dicho eje temporal los momentos pasados se funden con el presente conformando una unidad indisoluble que se caracteriza por el caprichoso ritmo de las vivencias. Surgen así, los momentos eternos, atemporales, plagados de sensaciones, de emociones y de sentimientos, momentos que se nutren del instante para recuperar el tiempo perdido en los anales de la memoria.

Este reencuentro con el pasado, clave en la obra de la escritora salmantina, se manifiesta en la configuración técnica de sus novelas y relatos, que se caracterizan por presentar una estructura generalmente analéptica. Por tanto, la disposición cronológica asume un orden alterado por frecuentes anacronismos retrospectivos, conformando una aglomeración de 
hechos pasados que, en ocasiones, se constituyen en el eje del relato, puesto que, tras un breve marco temporal en presente, se sucede una dilatada evocación. En El cuarto de atrás, por ejemplo, la narración aparece fragmentada por amplias y continuas referencias al pasado de la propia escritora, recuerdos añorados que surgen en unas horas de conversación con el misterioso hombre vestido de negro. Así , se configura poéticamente su infancia y su adolescencia, con sus ansias de comunicación y de libertad, sus temores, sus anhelos. Por último, su madurez, con sus reflexiones más profundas sobre el valor del tiempo, de la soledad y de la creación literaria.

"Variaciones sobre un tema" presenta también una estructura similar, puesto que prácticamente todo el relato se configura en el pasado, ya que Andrea intenta analizar el sentido de su vida indagando en su memoria. Todo se sucede, además, en escasos minutos, brevemente interrumpidos por los clientes que acuden al bar donde ella trabaja. Entre sonidos de platos y de tazas y el bullicio de las conversaciones, su mente viaja hacia su pasado. Sin embargo, sólo al final de esa pequeña odisea, la protagonista comprende que no necesita realizar un recuento que se limite simplemente a reseñar fechas, que los cinco años transcurridos en Madrid, al parecer, no dejaron huella en su memoria. Importaba más reencontrarse con sus vivencias, pues sólo ellas le permitirían habitar el tiempo, como sucedió en aquella ocasión, cuando contaba 15 años y su primera visita a la ciudad le causó un fuerte impacto emocional:

\begin{abstract}
"allí, a aquel cielo que fue propagando sus insensibles variaciones entre las ramas de los árboles hasta la total difuminación de toda luz y dibujo, y a las añoranzas de futuro que tal contemplación produjo en su mente de niña pueblerina, a aquellos últimos rojos de la tarde, alumbradores de anhelos y propósitos, era donde había que retroceder, a ese rescoldo- por fin estaba claro-, a buscar el rostro escondido de los cinco años, transformados más tarde, al ser verdad, en esta cuadrícula de fechas y sucesos que cualquier mediocre y ordenado cronista, sin gran esfuerzo, habría podido fielmente reproducir." (pp. 17-18)
\end{abstract}

Es significativo destacar, por otra parte, que practicamente todas las obras de Carmen Martín Gaite presentan una frecuencia escasa de acontecimientos, por tanto el tempo de sus novelas y relatos es moroso, dilatado, como corresponde a la reflexión, a ese bucear incesante por los profundos repliegues de la mente, donde a veces incluso se confunden el plano de la realidad con el de la fantasía, el sueño y el ensueño. No le interesa, por tanto, a la escritora forjar un universo narrativo donde impere la acción, pues sus novelas y relatos de carácter interiorizado se nutren más de emociones, sensaciones y sentimientos que se presentan a través de dilatadas pausas descriptivas. Así, por ejemplo, en El balneario se describen con minuciosidad las dudas y los temores de la señorita Eulalia que afloran a lo largo de una especie de viaje simbólico, en una atmósfera inquietante, donde se funden la fantasía y la realidad. De manera similar en "La oficina" se caracteriza la existencia monótona y vacía de Mercedes, a partir de una narración interiorizada que permite vislumbrar su dolor y su resignación ante el inexorable transcurso del tiempo, como sucede cuando contempla morosamente su imagen reflejada en el espejo:

"Muchas noches, al terminar sus tareas, Mercedes se encerraba con pestillo en aquel cuarto y se contemplaba el rostro atentamente, con los codos apoyados en el lavabo. Un rostro ancho, pasmado, de ojos enrojecidos que no expresaban ninguna 
cosa, un rostro que parecía recortado en cartón. Lo miraba como si lo viese cada noche por vez primera y necesitaba concentrarse trabajosamente para sentir de verdad que le pertenecía. Durante mucho rato se miraban los ojos de fuera y los del espejo se buscaban hasta acercarse y fundirse. Y los de dentro, pronto tenían a flor el hilo del llanto. Al menor temblor de las pestañas, la primera lágrima caía, dejando una huella seca y ardiente en la piel de la mejilla, un cauce tirante de sed que pedía más lágrimas. Era algo necesario y natural, como la lluvia. Lloraban largamente los ojos de Mercedes, sintiendo la compañía de aquellos otros del espejo, que por fin la habían reconocido." (p. 25)

En definitiva, las novelas, los relatos y los ensayos de Carmen Martín Gaite reflejan una honda preocupación por el tiempo. Los personajes que protagonizan su narrativa sientencomo la autora- sus efectos devastadores, su paso corrosivo e impasible, pero también experimentan una relación armoniosa que los proyecta hacia otra dimensión temporal más auténtica, más grata. Precisarente en esta experiencia positiva se encuentra la clave, el mensaje que la escritora salmantina deja traslucir a lo largo de su obra. Así, frente al acto destructivo de "matar el tiempo", propone el acto creativo de "habitarlo", de vivirlo, de valorarlo, de recrearlo poéticamente mediante la palabra, en esos momentos eternos, atemporales, en los que se produce el anhelado encuentro con el interlcsutor deseado, con nuestra verdadera identidad. Surgen, así, los recuerdos, los temores, los anhelos; sin embargo, como sugiere con acierto Carmen Martín Gaite en El cuento de nunca acabar, todo ello debe ser aderezado con los sentimientos, con la huella emocional que proyectaron en nuestras vidas, pues "El hilo de la memoria, aquel con que cosemos las historias de ayer con las de hoy y las propias con las ajenas, se ovilla en el corazón" (p. 325).

\section{BIBLIOGRAFÍA:}

ALEMANY BAY, C. (1990), La novelística de Carmen Martín Gaite, Ediciones de la Diputación de Salamanca.

BAQUERO GOYANES, M. (1963), Proceso de la novela actual, Madrid, Rialp.

BUTLER DE FOLEY, I. (1984), "Hacia un estudio del tiempo en la obra narrativa de Carmen Martín Gaite”, Ínsula, Madrid, nº 452-453, pág.18.

DURÁN, M. (1981), “Carmen Martín Gaite, Retahílas, El cuarto de atrás, y el diálogo sin fin”, Revista Iberoamericana, Pittsburgh, Vol.XLVII, núms. 116-117, pp.233-240.

GLENN, K. (1983), "Hilos, ataduras y ruinas en la novelística de Carmen Martín Gaite”, Novelistas femeninas de la postguerra española, Janet W. Pérez (ed.), Madrid, José Porrúa Turanzas, pp. 33-45.

MARTÍN GAITE, C. (1981), Retahílas, Barcelona, Destino.

(1981), Ritmo lento, Barcelona Bruguera.

(1982), La búsqueda del interlocutor y otras búsquedas, Barcelona, Destino.

(1988), El cuento de nunca acabar, Barcelona, Anagrama. 
(1992), Desde la ventana, Madrid, Espasa-Calpe.

(1994), Cuentos completos, Madrid, Alianza Editorial.

(1994), El cuarto de atrás, Barcelona, Destino.

MARTINELL, E. (1987), “Prólogo”, Desde la ventana, Madrid, Espasa Calpe.

MATAMORO, B.(1979), "Carmen Martín Gaite: El viaje al cuarto de atrás", Cuadernos Hispanoamericanos, Madrid, №351.

OLBA, M. (1984), “Carmen Martín Gaite: la lúcida aventura de escribir”, Ínsula, Madrid, $n^{\circ} 452-453$

PALLEY, J. (1980), "El interlocutor soñado de El cuarto de atrás, de Carmen Martín Gaite”, Ínsula, Madrid, N404-405

SOLER SERRANO, J. (1976), "Entrevista a Carmen Martín Gaite", A Fondo, Televisión Española.

VILLÁN, J. (1974), “Carmen Martín Gaite: Habitando el tiempo", La Estafeta Literaria, nº 549, Pág.21.

VILLANUEVA, D. (1975), "La novela irónica de Carmen Martín Gaite", Camp de l'arpa, Barcelona, $\mathrm{n}^{0}$ 23-24.

WOOLF, V. (1993), Orlando, Barcelona, Lumen. 
